\title{
Exploring the Use of Written Authentic Materials in ESL Reading Classes: Benefits and Challenges
}

\author{
Waheeb S. Albiladi ${ }^{1}$ \\ ${ }^{1}$ Curriculum \& Instruction, TESOL, University of Arkansas, Fayetteville, USA \\ Correspondence: Waheeb S. Albiladi, Curriculum \& Instruction, TESOL, University of Arkansas, Fayetteville, \\ USA.
}

Received: November 4, 2018

Accepted: December 6, 2018 Online Published: December 10, 2018

doi: $10.5539 /$ elt.v12n1p67

URL: https://doi.org/10.5539/elt.v12n1p67

\begin{abstract}
The growing popularity of authentic materials provides English language teachers with more resources to practice the real language in language classrooms (Guo, 2012). However, integrating these types of reading materials can be difficult and time-consuming even though there are many benefits to using them to teach language learners how to read. Real-life based texts, which are not specifically designed for educational purposes have been recognized by many educators to be effective and interesting materials. The purpose of this study was to explore language learners' perceptions about the benefits and challenges of using authentic materials in English reading classes. The study involved 16 adult English language learners enrolled in an intensive English program. Observations of reading classes and semi-structured interviews were used to collect the data. Results indicated that the use of authentic materials leads to many social and academic benefits, such as increasing students' motivation and their cultural awareness. Findings also suggest that the use of authentic materials are encouraged as they bring the sense of authenticity and reality to the language classrooms.
\end{abstract}

Keywords: authentic materials, reading materials, English teaching method, English reading, ESL, EFL

\section{Introduction}

\subsection{Background of the Study}

The purpose of reading in English as a second language (ESL) or English as a foreign language (EFL) classes is to improve students' skills so they can have access to the literature written in the target language (Nation, 2008). As such, students have been exposed to divergent reading materials to develop their reading skills. In particular, Singhal (2001) noted that some reading strategies emphasize the use of non-authentic or constructed texts. These texts can provide more meaningful and constructed language, helping to enhance many aspects of students' language learning, such as in grammar and vocabulary (Singhal, 2001). On the other hand, some recent reading strategies focus on providing students with texts that are directly taken from native speakers' daily lives. This method was used to link ELLs to the real language spoken by native speakers (Gilmore, 2007).

Accordingly, Peacock (1997) mentioned that the reading materials used in ESL/EFL classes can be classified into two different types of texts. The first type includes constructed or non-authentic texts. Peacock explained that these texts are designed especially for learning purposes and the language of these texts differs from the real-life language because it might be simplified, artificial, or concentrated on developing grammatical structures rather than reading skills. The second type of reading materials includes authentic texts. Harmer (1991) defined authentic reading materials "designed for native speakers; they are real text; designed not for language students, but for the speakers of the language" (as cited in Kilickaya, 2004. p. 1). Similarly, Zyzik and Polio (2017) defined authentic materials as "those created for some real-life purpose other than language learning, and often, but not always provided by native speakers for native speakers.” (p. 1). Tomlinson (2011) shared a more detailed definition of authentic materials that are the use for educational purposes:

A text which is not written or spoken for language teaching purposes. A newspaper article, a rock to.tg, "novel, a radio interview and a traditional fairy story are examples of authentic texts. A story written to exemplify the use of reported speech, a dialogue scripted to exemplify ways of inviting and a linguistically simplified version of a novel would not be authentic texts. (p. ix)

In other words, the differences between authentic and non-authentic materials are the audiences. Some examples 
of authentic texts, which teachers can use in ESL reading classes, are recent newspaper articles, daily magazines, advertisements, movie reviews, train schedules, and nutrition labels (Polio, 2014).

Although much research was done regarding using authentic materials in ESL/EFL classes, it is important to understand language learners' perceptions of using these materials, which is the focus of this study. There is a dearth of literature that examined how language learners perceive the written materials that are used in English classes. Hence, there is a dire need to explore these perceptions in hope of understanding the benefits and challenges of using these materials from students' perspectives. It is hoped that this will lead to enhancing the teaching methods that are used in English reading classes.

The present study was conducted to explore different types of materials that are used in ESL reading classes. McGrath (2013) noted that in language classes, materials play a critical role in English teaching and learning. Significantly, the study aimed to understand learners' preferences of the use of authentic written materials and their potential benefits on students' reading skills. This would inform English language learners as well as teachers, educators, and English program directors whether using these texts is the best way to enhance English language learners' (ELLs) reading abilities. By targeting the adult ELLs in this research, the study aimed to add to the research and offer a common basis for language teachers regarding the importance of using real-life language in ESL classes

\subsection{Research Questions}

The following questions guided this study:

1) What type of reading materials do language learners prefer to study and read in ESL reading classes?

2) What do language learners believe are the potential benefits of reading and integrating written authentic materials in and outside of ESL classes?

3) What do language learners believe are the challenges of reading and integrating written authentic materials in and outside of ESL classes?

\section{Literature Review}

Many second language educators agree that reading is one of the most essential skills a language learner should acquire because it facilitates mastering other skills (Horwitz, 2008; Krashen, 2007; Nation, 2008). Berardo (2006) mentioned that there are three purposes for reading: survival, learning, and pleasure. Each type has its own characteristics and motivations. In terms of reading for learning, reading is a fundamental skill that enhances students' oral and written abilities (Gilmore, 2007). A good reader usually becomes fluent in other language skills such as writing and speaking (Krashen, 2007). Moreover, reading for learning often occurs in classrooms and requires teachers and students to work extensively to develop these abilities (Berardo, 2006). Regarding second language learning, Horwitz (2008) indicates that reading can be the bridge that leads English language learners (ELLs) to obtain and master the language. Second language reading is an essential skill because it facilitates learning, helps second language learners gain academic success, develops language skills such as vocabulary and writing, and gives the opportunity to reduce social distances (Horwitz, 2008).

One way to develop language learners' reading abilities is to use real-life or authentic materials. Research has indicated that there are several advantages of using authentic texts in the language classrooms (Guariento \& Morley, 2001; Guo, 2012; Hwang, 2005; Kilickaya, 2004; Lin, 2004; W. C. Wu, \& P. H. Wu, 2008).

W. C. Wu and P. H. Wu (2008) noted that, because they are written for communicative purposes and given interesting themes, written authentic materials increase students' motivation. $\mathrm{Wu}$ and $\mathrm{Wu}$ added that these materials appeal to the students' interests, which motivates them to enhance their language skills through reading. Bererdo (2006) noted that students are usually motivated to read real-life texts, such as newspapers and magazines, because they are enjoyable and represent real life. Nuttal (1996) stated that "authentic texts can be motivating because they are proof that the language is used for real-life purposes by real people" (as cited in Bererdo, 2006. p. 64). Similarly, Oguz and Bahar (2008) stated that the use of authentic materials "connect the students to the social world and enable them to put their theoretical knowledge into practice, they open a way for positive transfer in learning. So authentic materials can increase the quality of foreign language teaching" (p. 334).

Accordingly, Guo (2012) examined the effects of using authentic materials on students' motivation. The research was conducted on fifty freshmen students from two different classes in a college in Taiwan over a period of three months. The two groups were given different reading materials. To illustrate, one group was given additional authentic materials that derived from daily newspapers and magazines, while the other group had only their 
reading textbooks. An attitude survey was given to each group after the end of the three months. According to Guo, students who had the additional authentic materials felt that the outside reading texts were more related to their lives and helped them enhance their understanding of the topics presented in these articles. In other words, they had positive attitudes toward these materials. Moreover, most students believed that additional authentic texts enriched their knowledge and motivated them to read more.

Moreover, Kilickaya (2004) emphasized the importance of utilizing authentic materials to teach both language and culture. Kilickaya noted that ELLs might explore different topics, situations, and forms of authentic text in the target cultural contexts. In other words, using authentic materials in teaching reading results in a more positive attitude toward the culture of the target language. Yu (2006) examined the cultural effects of using authentic materials with Taiwanese college students. This project was designed for two different classes for 36 weeks. At the beginning of the study, Yu provided students with a questionnaire. This pre-questionnaire was designed to examine students' understanding of American culture. During the class, students were given articles taken from the New York Times in their reading lessons. At the end of the study, Yu found that these articles led to a better understanding of American culture among the students. Yu continued that these articles allowed the students to understand and be familiar with the culture of English-speaking people.

In addition, Guariento and Morley (2001) indicated that authentic materials represent real-life outside the classroom. By integrating authentic texts in ESL classrooms, ELLs are given the opportunity to explore the language that is used daily by native speakers. According to Hwang (2005), although they are integrated inside classrooms, authentic reading materials help students who are studying English outside English-speaking countries to experience the language that is used there. These materials also help students to be close to the real language. Moreover, providing students with recent texts from newspapers, articles, or magazines allows students to know and learn about the current world. This knowledge will help them dive deep into the language and understand the way native speakers use it to communicate (Guariento \& Morley, 2001). In addition, Gilmore (2007) pointed out that authentic materials help decrease the gap between real languages and classroom languages. It also helps ELLs transfer what they have read into real-life situations.

Similarly, a survey study was conducted by Huang, Tindall, and Nisbet (2011) to explore the types of authentic materials that are used in ESL classes. In this study, more than thirty ESL teachers gave instances of authentic materials and activities that were effectively employed in ESL classes. These materials included five categories: "Employment, Technology, Consumer Goods, Consumer Services, and Citizenship/Civic Participation" (Huang, Tindall, \& Nisbet, 2011, p. 8). Thus, this wide range of sources gave ESL teachers the chance to connect students' language learning to the outside world in genuine communication (Berardo, 2006). Also, ESL teachers can benefit from this wide variety of sources to provide students with updated texts and texts that serve students' language needs (Polio, 2014).

Moreover, A study conducted by Akbari and Razavi (2016) examined EFL teachers' beliefs and attitude toward the use of authentic materials to develop the reading abilities of English language learners. The participants included 57 EFL Iranian teachers who completed a survey questionnaire related to the use of authentic material in language classes. The results indicated that the teachers had a positive attitude toward using authentic materials to teach English. The teachers perceived authentic materials as tools to improve students' language skills and linked them to the real language. The researchers mentioned that authentic materials can be used to develop students' reading skills more than any other language skills.

In conclusion, enhancing ELLs reading abilities is the focus of ESL classes because reading facilitates learning other skills, such as vocabulary and writing; helps second language learners to gain academic success, develops language skills; and gives individuals the opportunity to reduce the social gap (Horwitz, 2008). Thus, providing reading materials that motivate ELLs to read and enhance their reading skills has become a necessity. For many ESL educators, written authentic materials help students learn the language. These materials are interesting to read, related to students' lives, and can be used to develop other skills. The literature revealed that using authentic materials helps in conducting more effective and interesting reading classes. The literature also showed that using authentic materials motivates students to read more in the target language, relating students to the real language.

\section{Method}

\subsection{Study Design}

To understand the benefits and challenges of using written authentic materials in reading English classes from international students' perspectives, the research included 16 adult language learners from an intensive English program in the United States. According to Muchisky and Tangren (1999), an intensive English program is an 
academic program designed to serve students who are studying English as a second language in one of the English-speaking countries. These programs tend to enhance students' language skills to enable them to communicate fluently in English.

Because the research study aimed to understand the language learners' perspectives regarding authentic materials, a qualitative research method was used for this research study. Data collection methods included classroom observations for four different reading classes and face-to-face interviews with the participants. In terms of the observations, they were done to observe the written materials that were implemented in the classroom and to closely watch the students' reading and learning behaviors. Notes about how ESL teachers introduce these materials and how ELLs react with them were written during the classroom observation. Moreover, the purpose of the research interview was to elicit more information about the students' views on using written authentic materials in reading classes and the effects of these materials on their reading skills. ELLs were asked questions such as: What types of reading materials do you prefer to read? Why? What do you not like about reading each type? Do authentic materials motivate you to read more? Do you completely understand them? Do you think that reading real-life and daily texts helps you learn new and recent vocabulary words?

\subsection{Study Participants}

The study was conducted in four different advanced reading/vocabulary classes in an intensive English program in the United States. Students in these classes were required to demonstrate comprehension of authentic article-length texts by identifying the main idea and major and minor supporting sentences, writing an outline and one paragraph summary, paraphrasing, inferring the meaning of new words from contexts, and answering factual and inference questions.

The participants were 16 students, all of whom were adult English language learners. Eight students speak Arabic as a first language, while others speak languages including Chinese, Spanish, and Japanese. In other words, these participants came from a wide range of cultural and linguistic backgrounds. The students were diverse in their learning goals, some of whom will study for a bachelor's degree, whereas others will pursue masters degrees and Ph.D.'s at U.S. universities. The participants' ages range from 19 to 41 years old, and they differ in their learning backgrounds. The study included a mixed gender group with 8 females and 8 males. To ensure confidentiality, each student was assigned a pseudonym. Eight participants speak Arabic as their first language. I referred to these students as Roha, Ali, Mansour, Khalifa, Majid, Sana, Reem, and Ahlam. Other participants speak Chinese and Japanese, whom I referred to as Lin, Lue, San, and Fukima respectively. The final group of participants speak Spanish as a first language; I referred to them as Hana, Daniel, Dani, and Hanibal.

\subsection{Data Analysis}

Thematic analysis was used to analyze the collected data. Specifically, the data analysis process went through three phases. The first phase involved recording the interviews with participating ELLs. The recorded interviews were then transcribed verbatim. In the second phase, the researcher started the coding scheme. That involved reading through all transcribed interviews and assigning codes. After the initial coding, the third phase began with identifying recurring patterns and assigning categories. These categories were arranged systematically to larger more overarching categories and then summarized into themes and subthemes (see Table 1).

Table 1. The data analysis process with a sample of codes, categories and themes

\begin{tabular}{|c|c|c|c|}
\hline \multicolumn{4}{|c|}{ Samples of initial coding } \\
\hline \multirow{5}{*}{$\begin{array}{l}\text { encouragement } \\
\text { enjoyable } \\
\text { magazines } \\
\text { support fail } \\
\text { Reading level }\end{array}$} & "read more" & interaction & tural shock" \\
\hline & popular culture & shared beliefs & weekly news \\
\hline & recent articles & international & language level \\
\hline & knowledge motiva & grammatic & errors \\
\hline & appropriateness & understanding & culture \\
\hline & Categories & & \\
\hline Motivation & Types of authentic materials & Difficulty & Pedagogy \\
\hline & Themes & & \\
\hline & Types of authentic materia & & \\
\hline & Perceived benefits & & \\
\hline & Issues in using authentic mate & erials & \\
\hline
\end{tabular}




\section{Results}

The analysis of the data generated through the interviews with the participants revealed three overlapping and interdependent themes related to the use of written authentic materials as English teaching and learning tools. The first theme is types of authentic materials, which refers to different types of written materials that teachers use in reading classes. The second theme is the perceived benefits of authentic materials, which refers to the academic and social benefit that the participants believed are associated with authentic materials. The third theme is the issues of using authentic materials, which refers to what the participants believe are the challenges of using authentic materials in reading classes. In the following sections, each theme will be discussed extensively.

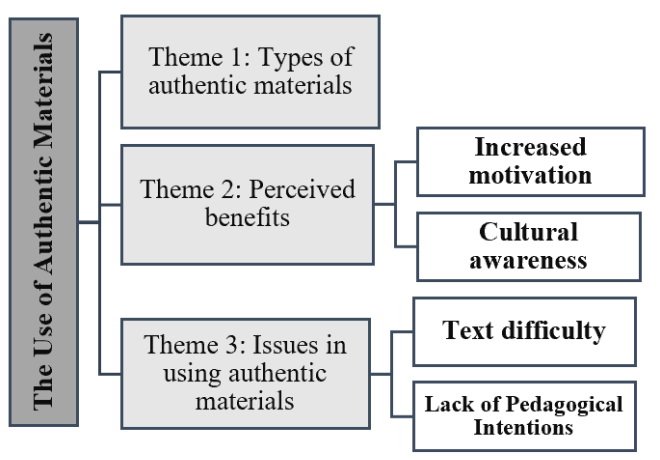

Figure 1. The themes and subthemes reflected from the research questions

\subsection{Theme1: Types of Authentic Materials}

The first theme emerged from data was different types of authentic materials. The participating language learners mentioned that they prefer to read many types of real-life materials in ESL reading classes. Particularly, the majority of students prefer to read current articles taken from their daily lives. This includes daily newspapers, weekly magazines, and advertisement papers. The students agreed that newspapers usually include interesting and enjoyable articles that discuss recent events. The participants consistently reported that these materials are motivating and increase their desire to read more. For example, multiple sources of authentic materials were mentioned in the participants' responses as these three participants indicated:

I prefer to read daily newspapers such as the Times, and our local newspaper. I like reading them in the class because they usually have interesting and enjoyable topics and themes that make us want to read more. Newspapers and magazines discuss really interesting topics. That is why we ask our teacher to read them [San]

Although reading required books, such as The Alchemist and Treasure Island, in the class benefit us, I think the class is more enjoyable when the teacher provides us with articles from different newspapers and magazines. These are current and discuss events that happened recently. The good thing is that I start to read them not only in class but also outside the class. [Lin]

To me, reading the advertisement books and the restaurant menus in the class was a good and creative idea because they are really interesting and motivating. We all liked to read them, but the teacher only used them two or three times. We usually read them outside, but the idea of reading and discussing them in reading classes is great [Dani]

In addition, it is clear that students are exposed to different types of authentic materials depending on the subject or the skills that are taught. In other words, the participating language learners believed that each type of text is used to serve a linguistic or pedagogical need, such as practicing different skills like skimming, scanning, paraphrasing, citing, summarizing, and outlining. As two students shared how using authentic materials helped him practice different reading skills:

I like not only reading the articles in the newspapers but also practicing my reading skills. Not long ago, my teacher asked us to read an article and try to answer some questions by scanning or skimming the whole article. There was a time limit to finish the activity. This helps me increase and develop my reading speed. [Ali] 
There are many kinds of texts that we read every single day. For example, I like reading weekly magazines such as the Times. It includes interesting and sometimes unexpected articles. We practice many reading skills after reading them. For instance, the teacher asks us to summarize or paraphrase a section of the article. [Reem]

To summarize, the participants noted that they prefer to read different types of authentic materials in ESL classes. Daily newspapers, magazines, and advertisement books were mentioned consistently as the most preferable types. According to the students, each type can be used for a different purpose.

\subsection{Theme 2: Perceived Benefits}

The second theme that emerged from the data was the perceived benefits of using authentic materials. The participating language learners believed that using authentic materials resulted in academic and social benefits related to teaching and learning English. Two subthemes were present in the teachers' and students' interview responses. The subthemes are increased motivation and cultural awareness.

\subsubsection{Increased Motivation}

Most of the participants felt that reading articles that are taken from recent newspapers or magazines increased their motivation to read, which enhanced their reading abilities accordingly. Students noted that they were eager to read more, which had many obvious benefits to their reading skills. They thought that, because they were reading a lot of authentic materials, both their reading speed and comprehension improved. As one of the students stated:

When I started reading newspapers and magazines in the class, my reading abilities have improved. I also started to read really fast. When our teacher gives us an article to read in class, I usually finish reading it and start to read other articles in the newspaper [Hanibal]

Unlike other reading materials, authentic or real-life texts motivated students to read more. Some students also reported that because they were motivated to read, the time that was needed to finish a whole article was reduced by half. For instance,

I had many reading difficulties at the low levels, but when I started to read more, my reading speed was really improved. One thing that encourages me to read is when teachers ask us to read the daily news. [Hana]

Additionally, the participants also believed that the use of authentic materials allows for more enjoyable and appealing reading classes. This motivates students to read and enjoy the class. For instance, one student mentioned:

Yes, I think using real and daily articles is really interesting. These materials make reading classes more interesting and enjoyable. When we read, we can understand what is happening in the world right now. This encourages us to read and interact in an enjoyable discussion. [Daniel]

All in all, one of the academic benefits of using authentic texts mentioned consistently by the students was increasing their motivation. Increased motivation can be seen as the participants' eagerness to read and discuss what they have read.

\subsubsection{Cultural Awareness}

A common benefit of using authentic materials shared by the participating students was increasing cultural awareness. Most of the participants reported that authentic texts allow for more understanding of the target culture. This was clear through some of the participants' responses to the effectiveness of using authentic materials on their knowledge and understanding of the American culture as explained by one of the students:

[Lue] Reading is one of the most important skills I work hard to develop. I usually read in and outside the classes because I know reading is the gate that leads me to master not only the language but also the culture.

[The researcher]: Could you give a specific example?

[Lue] Yes, I mean reading daily news allows me to know more about the popular culture and what is happening in the society. For example, last week, we read an article about the importance of "personal space" in American culture. This something I knew a little about when I started learning English.

Other participants mentioned that reading articles enabled them to understand many features of American culture, such as holidays and famous people. They read many articles that discuss the lives of American icons, such as Abraham Lincoln, Martin Luther King, and Lewis and Clark. This, according to the participants, resulted in more understanding of American culture. As one participant commented:

I believe that using current newspapers and magazines helps me understand how American people think and 
interact with each other. I mean, in every corner of the newspaper, I can learn new things about the history of this country. For example, I learned a lot about Martin Luther King from several articles I read in the class. Some of these articles talked about his personality as well as his contributions to the American society [Sana]

Fascinatingly, the participants also mentioned that one important benefit of increasing cultural awareness is avoiding or reducing the consequences of culture shock as described by one student:

One of the things that made me struggle as an English learner was not being able to start conversations with native speakers because I lack knowledge of the new culture. After reading many articles and news, I was able to start conversations and talk freely. This, in my opinion, led me to adapt to the new culture and avoid the cultural shock. [Mansour]

Ultimately, the participating language learners believed that reading and interacting with authentic or real-life materials increase their understanding of the culture. They were able to know more about different holidays, people, and events that are part of the American culture.

\subsection{Theme 3: Issues in Using Authentic Materials}

The third theme to emerge from the data was the addressing the challenges present when using authentic materials during reading ESL classes. Even though the participants believed that authentic or real-life materials have academic and social benefits on their learning, they shared some challenges that are associated with using these materials in ESL reading classes. The following subthemes summarized these challenges.

\subsubsection{Text Difficulty}

One of the most common challenges shared by almost all the participants is the difficulty of authentic materials. The students mentioned that some of these materials are difficult to read, and they struggle when asked to read in class. The difficulty can be caused by the lack of vocabulary knowledge that students have especially in the low-level English classes. As explained by one student:

Sometimes, we were asked to read an article or a piece of news during the class. These can be difficult to read because they include many new words that we have not studied yet. I like reading them, but sometimes I cannot understand most of it. Maybe because I am in the fourth level now. [Fukima]

Another reason behind this difficulty is that these materials are beyond students' proficiency levels as mentioned by a student:

Of course, there are some challenges to reading newspapers or magazines. The first thing that comes to my mind is the difficulty we face when reading some of these articles. I believe it is difficult to read because they include many vocabulary and words that we need to translate before reading them. [Majid]

Interestingly, there was a sense of frustration among the students caused by the text difficulty. This frustration leads to lack of motivation to read and complete the given tasks. For instance, one student stated:

Reading difficult text is really frustrating. I usually quit reading some articles because they can be difficult for me. I keep asking the teachers about the meaning of many words in the article. This caused me to stop reading. [Khalifa]

To summarize, text difficulty is one of the challenges of using authentic materials reported by the participants. The participants believed that some of the articles are beyond their proficiency levels. As such, this causes a sense of frustration and demotivation among the students.

\subsubsection{Lack of Pedagogical Intentions}

The language learners, while mentioning text difficulty as the main challenge, also consistently mentioned that the authentic materials they read in class lack pedagogical intentions. In other words, the participants believed that some of these materials contain unknown abbreviations, some slang words, and phrases that have a cultural association. This, according to some of the participants, made some of these articles not an ideal source of learning. For instance, one of the students explained:

Even though reading real articles in class is interesting, we sometimes face expressions or phrases that we do not understand. We have to stop reading and ask the teacher or search the meaning of this word. Some of these words are related to people's culture. For example, we read an article that includes some jokes. Almost all students in our class did not get these jokes. We could not understand them, so we asked the teacher to explain the jokes. Also, after the explanation, we could not get it. Sad isn't it? [Ali]

Another student commented: 
The only challenge that faced me when reading recent and real articles in reading classes is the use of slang phrases. Even though knowing these words helps us develop our language more, they disturb the flow of our reading. I mean, we had to stop and ask the teacher or ask my classmates to understand the meaning of them. [Reem]

Interestingly, one of the participants mentioned that some authentic materials used in reading class contain "grammatical errors." They had to stop reading and ask the teacher about these errors. They found out that there were some exceptions to the grammatical rule they knew and will study it at advanced language level.

One of the challenges that faced me when reading daily newspapers in class is the grammatical errors that we found. To be honest, not grammatical errors but some grammar "exceptions" as our teachers explained to us. We have not been introduced to these exceptions. [Khalifa]

All in all, one of the challenges that was reported in the data was the lack of pedagogical intentions. The participants believed that these materials contain abbreviations or words or phrases that they did not know about.

\section{Discussion}

The present study aims to explore the use of authentic materials in English reading classes. From the participants' responses and data, it is clear that the use of authentic materials in teaching English has become a necessity. Based on the narratives of the participants in this study, there are many obvious advantages and some disadvantages of reading and interacting with authentic texts in or outside of ESL classes. However, the academic and social benefits of using authentic materials outweigh its disadvantages.

First, the participants noted that they are exposed to different types of reading materials every day. These materials differ depending on the subject or the skills that are taught. In other words, each text is used to improve a certain reading skill or to serve certain needs of ELLs. The study found that daily newspapers and weekly magazines are the learners' most preferable choices due to the fact that these articles included many recent and interesting topics. The participants reported that they prefer to read these types of articles when introduced to new vocabulary or learners' reading skills including skimming, scanning, paraphrasing, citing, and finding the main ideas. Other types of authentic materials were welcomed by the learners. Many ESL teachers prefer to utilize authentic materials to teach reading because there are a variety of authentic sources that can be used in reading courses. For instance, newspapers, magazines, TV programs, train schedules, restaurant menus, advertisements, and hotel brochures are some of the most common authentic reading materials that can be used in teaching reading (Polio, 2014).

Regarding the benefits of using authentic materials, the study found that the use of authentic materials resulted in social and academic benefits, such as increasing motivation and cultural awareness. The majority of participant students agreed that using authentic texts in reading/vocabulary classes increased their motivation for further reading. According to the participants, this one of the most obvious benefits of integrating such materials. Increased student motivation was clear through the desire to read more of the articles provided by teachers. This finding resonates with research (Bererdo, 2006; Lin, 2004; Gilmore, 2007) that links using authentic materials with increased motivation. Nuttal (1996) stated that "authentic texts can be motivating because they are proof that the language is used for real-life purposes by real people" (as cited in Bererdo, 2006. p. 64). Moreover, Lin (2004) indicated that there is an increasing awareness of the importance of using authentic texts in classrooms to maintain and increase students' motivations to learn. Lin (2004) added that these texts give students the feeling that they are learning a real language and that they are in touch with the people or the context of the target language. Additionally, Gilmore (2007) pointed out that it is necessary for teachers of the second language to provide authentic materials inside classrooms to develop all the language skills because they are more motivating, engaging, and relevant to students' lives. This motivation will result in better learning and development in their language skills.

In addition to motivation, participants reported that the use of authentic texts in reading/vocabulary classes enhanced their cultural awareness. This finding resonates with the Kilickaya (2004) research, which perceives authentic materials as an effective tool for increasing the learners' cultural awareness. According to Kilickaya (2004), because authentic texts are designed for native speakers, English learners have opportunities to practice understanding the way people in the target language behave, giving them a glance of what they might face in the future. Additionally, understanding other cultures is not about understanding the food, import, export, and history of others, but also understanding the way people think and respond. In other words, by using language skills in combination with cultural skills, students can utilize their knowledge beyond the classroom.

In terms of the challenges, although most of the participants agreed on the advantages of reading authentic texts, 
they also reported some concerns about understanding these texts. Some students thought that many texts included words or phrases that they could not understand, causing them to question their reading abilities. Research (Lin, 2004; Tamo, 2009) has shown that text difficulty can be a challenge that hinders language learning. Lin (2014) mentioned that authentic materials might reduce learners' motivation because such texts are too difficult to read and understand by ELLs. Authentic texts are not necessarily meaningful or appropriate to the learners, especially learners with low proficiency levels. Reading for information, interest, or pleasure are the purposes of the fluent reader in real life. In comparison, for non-native learners, an important purpose in reading may be simply to learn the language. If an authentic text is too difficult, instead of helping ELLs to read for the meaning of the message, it will force the reader to focus on the form. When providing beginner language learners with authentic texts that include some structures that might be taught in the advanced levels, students will get confused and lose their motivation. This sense of frustration and confusion reduces opportunities for students' comprehensible input. To put it differently, the difficulty and complexity of authentic materials might be a challenge to learners' English proficiency levels. Unless they get an adequate pedagogical support from teachers, authentic materials might not help them be involved in the real language.

Another disadvantage of using authentic materials that was reported by the participants was the lack of pedagogical intentions for these materials. These materials are not designed for pedagogical purposes, which does not make them ideal sources of learning for language learners. Gilmore (2007) mentioned that most authentic texts are designed to be read for pleasure or for getting new information. These materials contain a language that is not written to teach or develop some of the language skills, such as grammar, reading, and writing. For non-native learners, an important purpose for reading or dealing with distinct texts may be simply to learn the language (House, 2008). Changing or modifying these materials can be a difficult task for language teachers due to the fact that, unlike constructed texts, authentic materials cannot be changed or modified depending on the learners' needs Similarly, Tamo (2009) indicated that because they are not designed to be learned, many authentic materials might be culturally biased. That is, they might include a language that can be culturally inappropriate for certain learners.

In order to avoid some of these challenges, Candy and Taylor (2006) suggested several questions that teachers should use as guidelines when choosing or creating authentic materials for ELLs. These questions include: (1) Are these materials suitable for the learners' proficiency level? (2) How appropriate are these materials or activities regarding students' age and maturity? (3) Are these materials relevant to students' interests? (4) What vocabulary words need to be pre-taught and introduced before assigning students to read these materials?

\section{Recommendations and Suggestions}

This study indicated several benefits of using real-life texts in ESL reading classes. These kinds of materials increased the authenticity of the class and thus motivated students to be engaged in the reading lessons. Thus, based on the learners' feelings and opinions about the effectiveness of these materials, several implications are suggested for ESL teachers and English language learners.

First, teachers should choose the materials that match students' proficiency levels. ESL Teachers should be aware that it is important to choose the texts that are comparable to the ELLs' reading abilities. In other words, ESL teachers should be more selective when choosing the correct materials for ELLs to read in ESL classes. As some students noted, some of the authentic materials contained language that was difficult for them to understand. They needed extra time to guess the meaning of some words that appeared in these articles, which disturbed the flow of their reading. There was a sense of frustration among some ELLs caused by the difficulty of some of the articles that they had to read.

Second, before reading the texts, ELLs should be introduced to any expression, word, or phrase that appears in the texts and has cultural associations. As participant students indicated, some authentic materials that they read included words that have cultural associations, which made it difficult for ELLs to read and understand these articles. Many participants did not have an adequate knowledge of the American culture, so they had difficulties understanding articles that contained cultural themes. As a way of illustration, many participants thought that some of the authentic texts that they read contained jokes, slang words, and words or phrases that have cultural associations. According to the participants, they had to ask their teacher to clarify and explain these expressions while they were reading. Therefore, before asking them to read, ESL teachers should read the materials first and discuss anything that has cultural implications. This will help students overcome any difficulties in understanding the provided articles.

Third, instead of only using articles from recent newspapers or magazines, teachers should diversify their choices of authentic materials. It is recommended that ESL teachers use a wide range of sources as authentic 
materials. English skills can be enhanced effectively when using a wide range of authentic materials. Thus, teachers should go beyond the limitations of constructed texts in ESL classes. The availability and diversity of authentic sources, which can be used in ESL classes, help ESL teachers to conduct more effective and appealing English classes. In other words, besides newspapers and magazines, teachers should provide students with other kinds of texts that are used in native speakers' daily lives, such as brochures, train or bus schedules, and movie brochures and descriptions.

Fourth, students should be encouraged to keep reading authentic texts not only in class but also outside ESL classes. From the participants' perspectives, reading authentic materials in reading/vocabulary class has many positive effects on their reading skills. Reading in the second language is the bridge that enables ELLs to acquire the language (Horwitz, 2008). Thus, when ELLs read authentic materials outside class, they will be in touch with the real language away from the classroom setting. When asking them about reading authentic materials outside classes, participants reported that they did not pay much attention to these kinds of materials outside classes. For instance, one of the participants mentioned that instead of reading the menus, she relied on pictures to order her preferred food in restaurants. Another student noted that he used to ignore the description of the items in most of the advertisement books. That is why ELLs should be encouraged to read these kinds of materials not only during English classes but also as a part of daily routines.

\section{Conclusion}

English language teachers need to be informed about the important role of reading in enhancing and developing other language skills. Many ESL teachers understand that if ELLs start to read in the target language, they will soon be able to master other language skills which enable them to communicate with the language (Krashen, 2007). However, choosing the most effective and beneficial materials for students to read in ESL classes can be challenging. The present study found that language learners are exposed to different types of authentic materials in ESL reading classes. They are required to read and analyze texts in order to match the proficiency level that enables them to develop their language skills. After analyzing students' responses, it can be said that authentic materials play an important role in enhancing and improving learners' reading skills. Providing students with materials they prefer, will motivate them to read, which helps in improving their English skills, accordingly.

The findings of this study are significant because they show how language learners perceive the materials used in most English classes. It is time that ESL teachers know and understand their students' preferences, regarding the materials that are used in ESL classes. Because this study aimed to identify the preferred language learning materials from learners' perspectives, it sheds light on the importance of incorporating students in the learning process. Asking students about their preferred materials to use will ensure a positive learning environment. Students' opinions, preferences, and ideas should be valued when deciding on the materials, methods, and sources incorporated in ESL classes.

Finally, the study involved some limitations. To begin, the results cannot be generalized because of the small sample size (16 English language learners) and the nature of qualitative research methodology. However, it can be argued that significant information was given by the participants regarding the use of authentic materials in English teaching and learning. Moreover, the present study did not answer the questions related to the effectiveness of using authentic texts for English language skills other than reading. Although students thought that these materials improved reading, they could not confirm whether these materials have an obvious influence on their overall language abilities. Thus, much research remains to be done on the effects of using real-life texts to enhance students' English skills such as writing and speaking. Similar research answers whether authentic materials can be used to improve overall language proficiency.

\section{References}

Akbari, O., \& Razavi, A. (2016). Using authentic materials in the foreign language classrooms: Teachers' perspectives in EFL classes. International Journal of Research Studies in Education, 5(2), 105-116.

Berardo, S. A. (2006). The use of authentic materials in the teaching of reading. The Reading Matrix, 6(2), 60-69. Retrieved from http://www.readingmatrix.com/articles/berardo/article.pdf

Candy, D., \& Taylor, R. (2006). Using authentic materials in the classroom: A webquest for teachers. Retrieved from http://www.theconsultants-e.com.

Gebhard, J. G. (2006). Teaching English as a foreign language: A teacher self-development and methodology guide. Ann Arbor, MI: The University of Michigan Press.

Gilmore, A. (2007). Authentic materials and authenticity in foreign language learning. Language Teaching, 40(02), 97-118. https://doi.org/10.1017/S0261444807004144 
Guariento, W., \& Morley, J. (2001). Text and task authenticity in the EFL classroom. ELT Journal, 55(4), 347-353. https://doi.org/10.1093/elt/55.4.347

Guo, S. (2012). Using authentic materials for extensive reading to promote English proficiency. English Language Teaching, 5(8), 196-206. https://doi.org/10.5539/elt.v5n8p196

Horwitz, E. K. (2008). Becoming a language teacher: A practical guide to second language learning and teaching. Boston, Ma: Pearson Education.

House, S. (2008). Authentic materials in the classroom. In R. Martinez (Eds.), Didactic Approaches for Teachers of English in an International Context (pp. 53-70). Universidad de Salamanca.

Huang, J., Tindall, E., \& Nisbet, D. (2011). Authentic activities and materials for adult ESL learners. Journal of Adult Education, 40(1), 1-10. Retrieved from https://files.eric.ed.gov/fulltext/EJ961996.pdf

Hwang, C. C. (2005). Effective EFL education through popular authentic materials. Asian EFL Journal, 7(1), 90-101. Retrieved from http://www.asian-efl-journal.com/March_05_ch.pdf

Kilickaya, F. (2004). Authentic materials and cultural content in EFL classrooms. The Internet TESL Journal, 10(7), 1-6.

Krashen, S. (2007). Extensive reading in English as a foreign language for adolescents and young adults. The International Journal of Foreign Language Teaching, 3(2), 23-29. https://doi.org/10.1016/S0346-251X(96) 00063-2

Lin, Y.F. The effects of authentic materials on motivation and reading achievement of EFL (English as aforeign language) learners in Taiwan. Ph.D. thesis, La Sierra University.

McGrath, I. (2013). Teaching materials and the roles of EFL/ESL teachers: Practice and theory. New York, NY: Bloomsbury Academic

Muchisky, D., \& Tangren, N. (1999). Immigrant student performance in an academic intensive English program. Generation 1.5 meets college composition: Issues in the teaching of writing to US-educated learners of ESL, 211-234.

Nation, I. S. (2008). Teaching ESL/EFL reading and writing. New York, NY: Routledge Publication.

Oguz, A., \& Bahar, H. O. (2008). The importance of using authentic materials in prospective foreign language teacher training. Pakistan Journal of Social Sciences, 5(4), 328-336.

Peacock, M. (1997). The effect of authentic materials on the motivation of EFL learners. ELT Journal, 51(2), 144-156. Retrieved from https://doi.org/10.1093/elt/51.2.144

Polio, C. (2014, May). Using authentic materials in the beginning language classroom. Clear News, 18(1), 2-3.

Singhal, M. (2001). Reading proficiency, reading strategies, metacognitive awareness and L2 readers. The Reading Matrix, 1(1), 1-8.

Tamo, D. (2009). The use of authentic materials in classrooms. Linguistic and Communicative Performance Journal, 2(1), 74-8.

Tomlinson, B. (Ed.). (2011). Materials development in language teaching. Cambridge, UK: Cambridge University Press.

Wu, W. C., \& Wu, P. H. (2008). Creating an authentic EFL learning environment to enhance student motivation to study English. Asian EFL Journal, 10(4), 211-226.

Yu, H. C. (2006). A case study in the application of authentic materials texts. Canadian Social Science, 2(6), 23-31.

Zyzik, E. C., \& Polio, C. (2017). Authentic materials myths: Applying second language research to classroom teaching. Michigan, MI: University of Michigan Press. https://doi.org/10.3998/mpub.7892433

\section{Copyrights}

Copyright for this article is retained by the author(s), with first publication rights granted to the journal.

This is an open-access article distributed under the terms and conditions of the Creative Commons Attribution license (http://creativecommons.org/licenses/by/4.0/). 